\title{
Application of Ecological Constructivism Situation Design in VB Program
}

\section{Course}

\author{
Jin Ling \\ College of Information Engineering, Jiangxi College of Technology, Jiangxi Nanchang 330098
}

Keywords: Constructivism; Situation design; VB program course

\begin{abstract}
Professor He Kekang thinks that scenario creation is the most important contents in constructivism teaching design. Based on this, this article is dedicated to creating ecological constructivism teaching situations. After many years of teaching practice and summary, several typical teaching situations were created for VB programming. Therefore, the article provides teachers with guidance and reference for creating ecological constructivism teaching situation and also the students with new methods and thoughts for self-construction ability.
\end{abstract}

\section{Introduction}

Traditional VB program courses often neglect the design of teaching situations, and the teaching activities lack corresponding situations, which finally don't lead to ideal teaching effect. In terms of teaching contents, there courses always explain scattered statement and algorithms, neglecting the effective link between programming knowledge. As a result, students fail to create a knowledge system through forward-backward correlation of knowledge. In terms of teaching mode, students still are the passive receiver of knowledge, which results in lack of vitality and creation, low interest of students in the study, students' failure to effectively take part in the study, and further unsatisfactory teaching effect.

As a new teaching theory, constructivism puts forward a series of new ideas in the views of knowledge, study, evaluation, etc. and is listed by American AECT (Association for Educational Communications and Technology) as an important research finding in the fields of educational communication and technology [1]. The theory thinks that knowledge is obtained by students by using study resources and through coordination under a certain situation. During the course of teaching, a teacher should provide students with various kinds of resources (including all kinds of teaching materials and media) and encourage the students to complete meaning creation by using a teaching situation and through active exploration so as to reach their study objective [2]. Therefore, when making teaching design, the teacher should create a learning situation favorable to meaning construction by students and take such situation as the one of the most important contents of the teaching design.

VB programming is a course with strong practicality. Only after the students complete study tasks can they make self-exploration and research gradually. Therefore, teaching tasks in real image become important conditions for active construction by students; these tasks, however, are included in teaching situations; thus creating concrete, real, rich and diversified teaching situations become a necessary condition. By using real situations, the teacher is able to lead students to experience the 
thinking of programming, simplify and reflect programs and improve programing ability gradually, thus reaching good study effect.

The article designs a series of ecological constructivism teaching situations and introduces them into teaching courses. The result of the comparison test conducted in Civil Engineering major of Jiangxi University of Technology shows that ecological constructivism situation teaching has an obvious effect in improvement of students' grades and satisfaction of course teaching.

\section{Ecological constructivism situation design}

Professor Gu Mingyuan thinks that situation teaching is a teaching method which arouses active learning interest of students and improves learning efficiency by using concrete vivid situations [3]. Teacher Zhu Yongyu brought forward in the research that the design of teaching situations should focus on creating real or emulational study situations and set different study situations based on diversified demands in self-study, cooperation study, etc. [4]

Using the experience of the above thoughts for reference, the article puts forward a new teaching situation design method, namely ecological constructivism situation design, which incorporates ideas such as ecological views of development, dynamics, etc. into the design of teaching situations, taking such design as a multicomponent complex but also a universally associated ecosystem.

In teaching practice, the design of ecological constructivism situation should be made mainly in the following aspects:

1) Create a teaching situation by using incorrect "traps"

Trap students by using ingeniously designed traps in teaching design to draw their attention, mobilize their cognition drive and promote them to actively and efficiently perform active knowledge construction.

In the following trap example, as long as a value more than 70 is input, each result is "Grade $\mathrm{C}$ ". Students question the result. But after testing two kinds of examples by themselves, they understand the implications in the program execution process: once the first condition is met, the first statement will be executed. After such execution, the next condition will not be judged and the program exits such structure directly.

\begin{tabular}{|c|c|}
\hline Examples of correct & trap example \\
\hline If $x>=90$ Then & If $x>=70$ Then \\
\hline Text2.Text $=$ " Grade $A "$ & Text2.Text $="$ Grade $C "$ \\
\hline ElseIf $x>=80$ Then & ElseIf $x>=80$ Then \\
\hline Text2.Text = " Grade B" & Text 2. Text $="$ Grade $B "$ \\
\hline ElseIf $x>=70$ Then & ElseIf $x>=90$ Then \\
\hline Text2.Text = " Grade C" & Text2.Text $="$ Grade $A "$ \\
\hline End If & End If \\
\hline
\end{tabular}

Thereafter, an input negative generates no an output result. A contradictory problem occurs again and students fall into the trap set by the teacher again. At this time, the teacher can prompt students to realize the function of the program by using a nested case structure, and students practice again. Gradually extend the difficulty and scale of the program through small problems occurring 
constantly. In this way, naturally doing expansion exercises of new and old knowledge points and reorganization of cognition structure from simple to complex makes students deny and surpass themselves continuously and realize self-development. These also are a reflection of ecological constructivism development principle.

2) Create teaching situations by using progressive case links

A screen with "scrolling words" is a programming application which can be seen everywhere. Arouse the desire of students to obtain knowledge using this case and then add the functions of the program to form a progressive case link in a bid to make students perform observation and analysis, explore the relations and rules between knowledge, and learn to make discrimination, thinking and application, and at the same time, to make students form a stable chain system structure of knowledge in a progressive manner.

2) Create teaching situations by using ill-structured problems

Problems with multiple solutions or solving methods, without solutions or with many answers are a subset of an ill-structured problem. In VB programming, some problems such as calculating the sum of "1-2+3-4+.....+99-100" by using a "print pyramid" program, etc. can be realized via many kinds of methods. Designing teaching situations by using such problems can lead to discussion and communication among students and cultivate divergent and creative thinking. Students are expected to structure problems they meet in different manners and form a solution to solve ill-structured problems through discussion and communication in the process of structure; to verify and improve the scheme and finally form a strategy for solving ill-structured problems; and to design such strategy into figures and apply them into the study of other knowledge.

\section{Teaching effect}

During the teaching reform test, the ecological situation teaching method was used in pilot classes (Classes 7, 8 and 9 of Civil Engineering entered the college in 2013, while the traditional teaching method in comparison classes (Classes 1, 2 and 3 of Civil Engineering of 2013, and Classes 2 and 3 of Engineering Management of 2012). After doing so for half a year, objective analysis was made over the final exam results of the two kinds of classes, and the result shows, as indicated obviously in Fig .1, that the exam results of pilot classes are higher than that of non-pilot classes, indicating that ecological constructivism situation teaching really has a noticeable promotion effect on learning effect. 


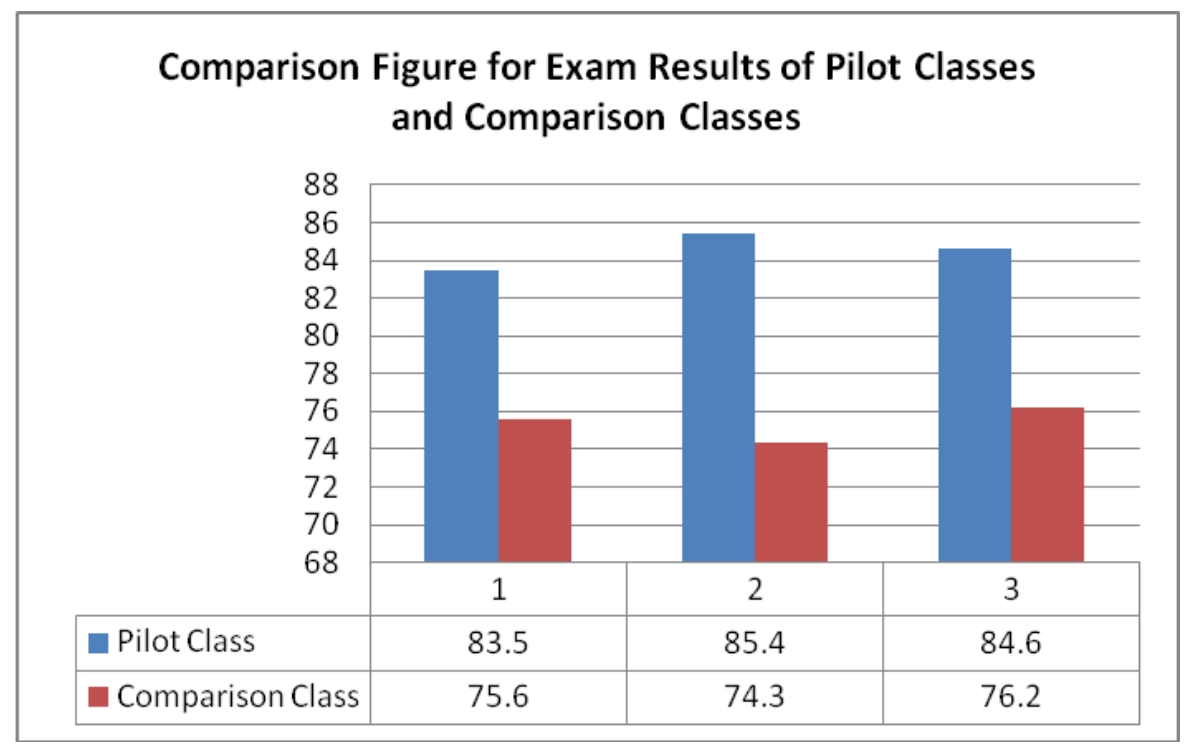

Figure. 1 Comparison Figure for Exam Results of Pilot Classes and Comparison Classes

At the same time, a questionnaire survey was carried out in three pilot classes. 30 students were randomly selected from each class to participate in the survey. Totally 86 effective questionnaires were returned which accounts for $95.6 \%$ of issued questionnaires. The questionnaire survey covers direct feelings such as the recognition, acceptance, satisfaction and participation of students on situation teaching. The result of the survey shows that students hold positive altitude to ecological constructivism situation teaching ( see Fig .2 below) .

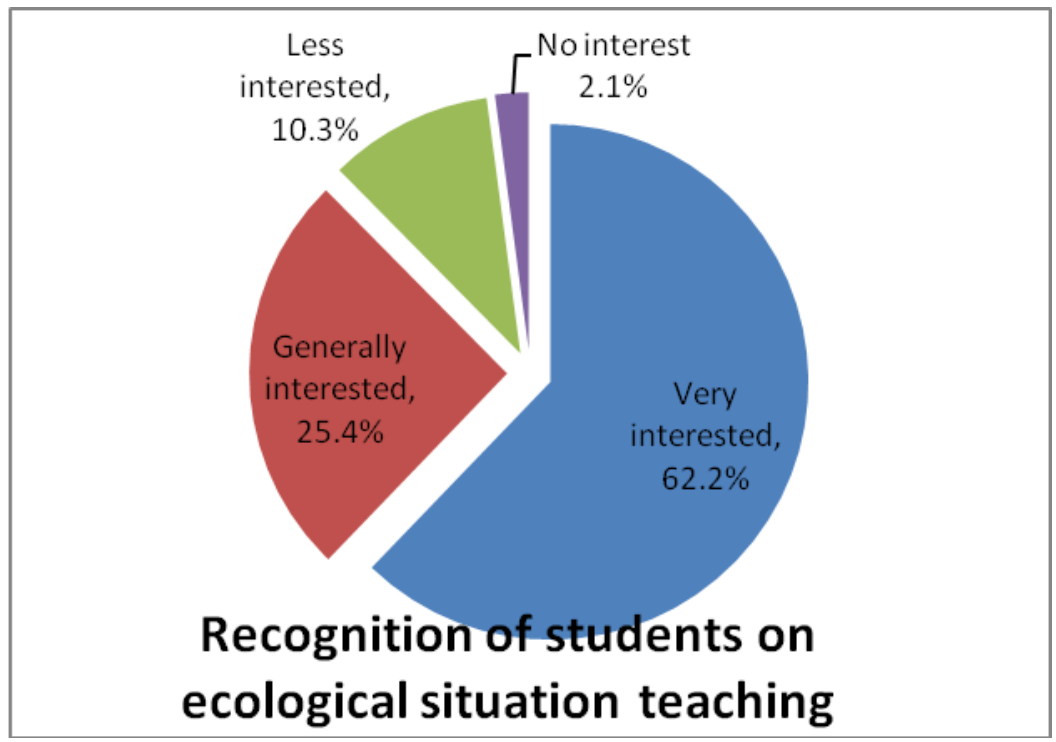

Figure. 2 Recognition of Students on Ecological Situation Teaching

\section{Conclusion}

From the standpoint of education ecology, the design of ecological constructivism situation adds ecological elements into situation creation in an effort to realize ecological balance in teaching 
situations, arouse the desire of students to pursue knowledge to the maximum extent and make them actively complete meaning construction when they want to learn and enjoy learning.

For teachers, the design process of ecological teaching situations is also a self-enrichment, self-accumulation and self-improvement process. Teachers should continuously integrate course contents and ecological constructivism teaching design thinking and create more teaching situations so as to make students realize self-construction in ecological diversified situations lightly and more importantly to make students convert their self-construction ability to the study ability for a life time.

\section{Acknowledgment}

This article sets out the research results of class culture construction research in the perspective of ecological philosophy (Subject No.: XYSKYB1307) studied by Department of Humanities and Social Sciences of Jiangxi University of Technology, and the research results of the excellent course, Fundamentals of Computers in Jiangxi.

\section{References}

[1] He Kekang, One of Study and Thinking of the 3rd Edition of Handbook of Research for Educational Communications and Technology- Deepening of knowledge of Constructivism Study Principle and constructivism Teaching Design [J], E-education Research, 2013(07):5-10.

[2] Yang Jingyi, College English Situation Teaching Design Based on Constructivism Theory [J], Journal of China Institute of Industrial Relations, 2011(04):107-109

[3] Gu Mingyuan, Comprehensive Dictionary of Education [M], Shanghai: Shanghai Educational Publishing House, 1999

[4] Zhu Yongyu, Practice on Creation of Teaching Situations in Higher Vocational Education Project-based Teaching, 2011(11): 29-31

[5]Wilson J S, Stocking V B, Goldstein D. Gender differences in motivations for course selection: Academically talented students in an intensive summer program[J]. Sex Roles, 1994, 31(5-6): 349-367.

[6]Chitwood Jr W R, Nifong L W, Chapman W H H, et al. Robotic surgical training in an academic institution[J]. Annals of surgery, 2001, 234(4): 475.

[7]Elkin I, Shea M T, Watkins J T, et al. National Institute of Mental Health treatment of depression collaborative research program: General effectiveness of treatments[J]. Archives of general psychiatry, 1989, 46(11): 971-982.

[8]Brown V B, Ridgely M S, Peppe B, et al. The dual crisis: Mental illness and substance abuse: Present and future directions[J]. American Psychologist, 1989, 44(3): 565.

[9]Schrauwen-Hinderling V B, Schrauwen P, Hesselink M K C, et al. The increase in intramyocellular lipid content is a very early response to training $[\mathrm{J}]$. The Journal of Clinical Endocrinology \& Metabolism, 2003, 88(4): 1610-1616.

[10]Unnithan V B, Katsimanis G, Evangelinou C, et al. Effect of strength and aerobic training in children with cerebral palsy[J]. Medicine and science in sports and exercise, 2007, 39(11): 1902-1909. 